Research paper

\title{
Deflector-jets affected by pre-aerated approach flow
}

\author{
MICHAEL PFISTER (IAHR Member), Laboratory of Hydraulic Constructions (LCH), Ecole Polytechnique Fédérale de Lausanne \\ (EPFL), CH-1015 Lausanne, Switzerland.
}

Email: michael.pfister@epfl.ch (authorfor correspondence)

WILLI H. HAGER (IAHR Member), Laboratory of Hydraulics, Hydrology, and Glaciology (VAW), ETH Zurich, CH-8092 Zürich, Switzerland.

Email: hager@vaw.baug.ethz.ch

\begin{abstract}
Jets generated at chute ends move a potential scour zone away from the dam, and dissipate flow energy to reduce the scour. Usually, so-called flip buckets or ski jumps are provided to generate jets, yet they are rarely issued by deflectors. The application of a theoretical mass point parabola is limited to predict the jet features, because effects related to the take-off angle and the disintegration process affect the jet air transport and trajectories. This research discusses the effect of pre-aeration of the approach chute flow on the jet features. A comparison with a former study indicates that mainly the upper jet portion is affected, that the black water jet core becomes shorter, and that the air transport increases. Although the lower trajectory is less affected and thus remains more coherent, the small effect of pre-aeration is sufficient to reduce the total jet throw length, so that pre-aerated jets tend to be shorter as compared with black-water approach flow jets, in agreement with prototype observations.
\end{abstract}

Keywords: Air concentration, chute, deflector, jet, pre-aeration, trajectory

\section{Introduction}

Free jets are generated at the end of chutes or at bottom outlets to direct the discharge to a plunge pool, where the residual flow energy is dissipated (Rajaratnam 1976, Vischer and Hager 1995). Excessive scour near the dam foot or other hydraulic structures is thereby avoided and dam safety is not constrained. These jets typically disintegrate in the streamwise direction and expand, decreasing the jet density by air entrainment. Both, the resulting larger jet-footprint on the plunge pool surface and the decreased jet density reduce their scour potential (Pagliara et al. 2006), or may amplify rock scour (Bollaert and Schleiss 2003a, 2003b). The latter phenomenon follows from the reduced speed of sound in the mixture flow, generating lower dynamic frequencies within the fissures that may stimulate the latter to resonance, thereby enhancing block separation and finally uplift.

Jets are typically generated using various chute end structures, as flip buckets (Khatsuria 2005, Novak et al. 2007) or deflectors (Steiner et al. 2008). They have in common that the flow is deviated and the take-off angle increased, so that the throw length increases as compared with chute ends without these structures. Flip buckets allow for a high jet deviation angle, while that of deflectors is smaller but they are simpler to build. A small deviation angle may be advisable for limited plunge pool dimensions (Pfister et al. 2009). The air transport characteristics of jets was described by Toombes and Chanson (2007) for jets issued at bottom outlets, and by Schmocker et al. (2008) for flip bucket-generated jets.

A preliminary study on deflector- and drop-generated jets analysed the streamwise air concentration characteristics and the jet trajectories, based on a systematic variation of the relevant geometrical and hydraulic parameters (Pfister and Hager 2009a, 2009b). The trajectories were normalized with the takeoff coordinates and the maximum (subscript $M$ ) jet elevation, connecting these two points with a parabola. The uncertainty related to the flow take-off angle, which differs from the terminal structure angle (Orlov 1974, Pfister 2012), was thereby taken into account. The air concentration development depends on the jet black-water core length, based on which equations for the streamwise increase of average (subscript $a$ ) and minimum (subscript $m$ ) jet air concentrations were derived.

The effect of pre-aeration on the jet was ignored so far. Particularly on relatively long and steep chutes with small discharges, uniform flow occurs at the chute end, so that the approach

Revision received 12 January 2012/Open for discussion until 31 October 2012. 


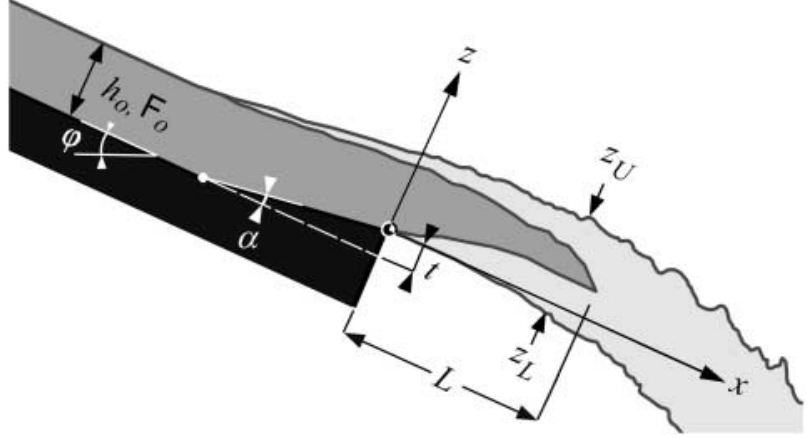

Figure 1 Definition sketch with notation

flow just upstream of jet take-off is pre-aerated. The degree of pre-aeration may be considerable mainly for steep chutes, resulting in a relevant effect on the jet features. Thus, the goal of this study is to describe the effect of pre-aerated approach flow on the jet features, mainly in terms of its streamwise air concentration development and the jet trajectories, as compared with jets of non-aerated approach flow.

\section{Hydraulic model}

\subsection{Model set-up}

Additional experiments were conducted in the sectional chute model at the Laboratory of Hydraulics, Hydrology, and Glaciology (VAW), ETH Zurich, which was previously used for the related basic study (Pfister and Hager 2009a, 2009b). The model consisted of a $6 \mathrm{~m}$ long and $0.3 \mathrm{~m}$ wide channel, with a jet-box as inlet. Various deflectors were mounted at the end of a $2 \mathrm{~m}$ long approach flow reach, from where the jets were issued (Fig. 1). To generate long jets, the chute bottom downstream of the deflectors was lowered.

In addition to the basic study, pre-aerated approach flow was generated upstream of the tested deflectors (Pfister et al. 2011), so that the related jet characteristics could be compared with those of the non-aerated black-water approach flow of the basic study. The average approach (subscript $o$ ) flow air concentration $C_{a o}$ was systematically varied $\left(0.04 \leq C_{a o} \leq 0.25\right)$, measured $0.3 \mathrm{~m}$ upstream of the deflector lip. The minimum relates to non-aerated approach flow with a slightly-roughened flow surface, generating a small average air concentration, as in the basic study, while the maximum is close to the uniform (subscript $u$ ) flow average air concentration $C_{a u}$ for the present model set-up.

Flows of variable approach flow depths $h_{o}$ and Froude numbers $\mathrm{F}_{o}=V_{o} /\left(g h_{o}\right)^{1 / 2}$ were generated, where $V_{o}=$ approach flow velocity and $g=$ gravity acceleration. Both $h_{o}$ and $\mathrm{F}_{o}$ relate to the non-aerated black-water approach flow. The mixture flow depth $h_{90}$ associated with the two-phase flow depth is defined from the chute bottom to the free surface with an air concentration of $C=0.90$. Beside $\mathrm{F}_{o}, h_{o}$, and $C_{a o}$, two additional parameters affecting the jet air characteristics were varied, namely the deflector height $t$ and the deflector angle $\alpha$ (Fig. 1, Table 1). The pressures below and above the jet were atmospheric, i.e. did not
Table 1 Test programme

\begin{tabular}{lcccccc}
\hline Series & Test & $C_{a o}[-]$ & $\mathrm{F}_{o}[-]$ & $h_{o}[\mathrm{~m}]$ & $\alpha\left[^{\circ}\right]$ & $t[\mathrm{~m}]$ \\
\hline S1 & 164 & 0.04 & 7.5 & 0.065 & 5.7 & 0.013 \\
& 165 & 0.21 & 7.5 & 0.066 & 5.7 & 0.013 \\
& 166 & 0.17 & 7.4 & 0.066 & 5.7 & 0.013 \\
S2 & 167 & 0.04 & 7.6 & 0.065 & 11.3 & 0.013 \\
& 168 & 0.21 & 7.6 & 0.064 & 11.3 & 0.013 \\
& 169 & 0.15 & 7.7 & 0.064 & 11.3 & 0.013 \\
S3 & 170 & 0.06 & 8.9 & 0.066 & 5.7 & 0.013 \\
& 171 & 0.25 & 9.3 & 0.064 & 5.7 & 0.013 \\
& 172 & 0.14 & 9.1 & 0.066 & 5.7 & 0.013 \\
S4 & 173 & 0.06 & 8.0 & 0.080 & 5.7 & 0.013 \\
& 174 & 0.21 & 8.1 & 0.080 & 5.7 & 0.013 \\
& 175 & 0.13 & 8.2 & 0.080 & 5.7 & 0.013 \\
S5 & 176 & 0.06 & 8.9 & 0.066 & 5.7 & 0.027 \\
& 177 & 0.24 & 9.1 & 0.065 & 5.7 & 0.027 \\
& 178 & 0.15 & 9.1 & 0.065 & 5.7 & 0.027 \\
S6 & 179 & 0.04 & 6.2 & 0.064 & 5.7 & 0.013 \\
& 180 & 0.21 & 6.3 & 0.064 & 5.7 & 0.013 \\
& 181 & 0.17 & 6.3 & 0.063 & 5.7 & 0.013 \\
\hline
\end{tabular}

affect the jet features, and the chute bottom angle was constant at $\varphi=12^{\circ}$ relative to the horizontal. Series consisting of three tests were conducted, in which exclusively $C_{a o}$ was varied, while the other parameters were kept constant. Then the isolated effect of $C_{a o}$ on the black-water core length, the minimum and the average air concentrations, as well as on the trajectories resulted.

Unit discharges between 0.19 and $0.58 \mathrm{~m}^{3} / \mathrm{sm}$ were tested and measured with an electromagnetic flowmeter (Krohne, Germany). The black-water approach flow depth $h_{o}=h_{90}\left(1-C_{a o}\right)$ was derived from air concentration data providing $C_{a o}$ and $h_{90}$. The two-dimensional jet air concentration distribution was measured, using a dual fibre-optical probe, providing the totally conveyed air (RBI Instrumentation, France). Additionally, a second fibre-optical probe was inserted into the approach flow to derive $C_{a o}$. The air concentration measurement grid space was $0.20 \mathrm{~m}$ in the streamwise direction $x$, and $2-3 \mathrm{~mm}$ along $z$. The pre-aerated approach flow was generated by supplying pressurized air into the jet-box, which produced a fully-developed turbulent flow at the deflectors.

\subsection{Turbulence estimation}

The chute flow turbulence upstream of jets affects their disintegration process. As turbulence was not measured, it was estimated based on the uniform flow shear velocity as

$$
U^{*}=\sqrt{g R_{h} S_{o}}
$$

where $R_{h}=$ hydraulic radius and $S_{o}=$ chute slope. Falvey and Ervine (1988) propose a normal fluctuating velocity (rms of velocity fluctuations) $v^{\prime}=U^{*}$ for boundary layer shear flows, whereas Nezu and Nakagawa (1993) propose a similar value of 
$v^{\prime}=1.27 U^{*}$. The latter results in a turbulence intensity $\mathrm{T}_{o}$ of

$$
\mathrm{T}_{o}=\frac{v^{\prime}}{V_{o}}=\frac{1.27 U^{*}}{V_{o}}
$$

The values computed with Eq. (2) are of the order of $\mathrm{T}_{o}=$ $0.05 \ldots 0.08$. This corresponds to the turbulence level at the chute bottom immediately upstream of the jet take-off, computed for black-water flow conditions for the normal turbulence component. To obtain turbulence-induced surface air entrainment, Falvey and Ervine (1988) propose $V_{o} /\left(0.24 \mathrm{~T}_{o}^{-1}\right)>1 \mathrm{~m} / \mathrm{s}$, which is satisfied with $1.61-1.75 \mathrm{~m} / \mathrm{s}$ for all present tests.

\subsection{Scale effects}

A dynamic similarity of free-surface aeration for water-jets is impossible for geometrical similar models because the internal jet turbulence represented by the Reynolds number $\mathrm{R}_{o}=V_{o} h_{o} / v$ is underestimated, while the surface tension represented by the Weber number $\mathrm{W}_{o}=V_{o} /\left[\sigma /\left(\rho h_{o}\right)\right]^{1 / 2}$ is overestimated (Ervine and Falvey 1987). Here, $v=$ kinematic viscosity, $\rho=$ density, and $\sigma=$ surface tension of water. The additional tests relating to pre-aeration ranged within $144 \leq \mathrm{W}_{o} \leq 240$ and $2.8 \times 10^{5} \leq$ $\mathrm{R}_{o} \leq 5.2 \times 10^{5}$, which is considered sufficient to avoid significant scale effects (Pfister and Hager 2010, Pfister and Chanson 2012). The tests involved a large-scale model, as recommended by Toombes and Chanson (2007). Scale effects relative to jet trajectories were discussed by Juon and Hager (2000) and Heller et al. (2005), recommending for water jets in the atmosphere $h_{o} \geq 0.05 \mathrm{~m}$ and $h_{o} \geq 0.04 \mathrm{~m}$, respectively. As a consequence, the primary jet disintegration, i.e. the disintegration of the jet itself, seems well-represented in the model. This statement is supported by the jet break-up types of Ohnesorge (1936), indicating that the model and the comparable prototype jets establish the disperse disintegration type (Vischer and Hager 1995). Considering jet disintegration in detail indicates that two mechanisms occur, namely primary and secondary jet disintegration.

The primary jet disintegration is caused by (e.g. Baumgarten 2003): (1) flow turbulence resulting from chute flow upstream of jet take-off, (2) aerodynamic interaction between the jet and the surrounding air, and (3) relaxation of the velocity profile. A consideration of the jet turbulence in the streamwise direction by Schley (1994) and Ervine et al. (1995) indicates that the turbulence degree decreases, and that the size of a turbulence cell increases, tending to cover the entire section. Beyond a jet length of some 400 initial nozzle diameters, Schley (1994) observed homogenized jet turbulence. This indicates that the primary disintegration requires a certain developing length, or vice versa, it mainly takes place in the first jet reach.

The secondary disintegration of water packages separated from the jet under the aerodynamic interaction cannot be represented correctly in a scale model. The drop (subscript $D$ ) Weber and Laplace numbers characterize the stability and break-up mechanisms subjected to aerodynamic effects, with $\mathrm{W}_{D}=\left(v^{2} \rho_{A} D\right) / \sigma$ and $\mathrm{L}_{D}=(\rho \sigma D) / \eta^{2}$. Here, $D=$ drop diameter, $v=$ relative velocity between the air and a drop, and $\eta=$ dynamic viscosity. Symbols without subscript relate to the fluid, and subscript $A$ to air parameters. In general, drops remain stable if $\mathrm{W}_{D}<10-12$, whereas they break-up by different mechanisms for higher values (Krzeczkowski 1980, Hwang et al. 1996). Volkart (1980) observed in self-aerated model flows that ejected drops "larger than $6 \mathrm{~mm}$ [...] become parted". Taking this diameter as the basis for a stable drop and $v=10 \mathrm{~m} / \mathrm{s}$ indicates that $\mathrm{W}_{D}=10$ on models, while $\mathrm{W}_{D}=1000$ in a prototype for $\lambda=10$, with $\lambda=$ geometrical scale factor for Froude similitude. Such a prototype drop would disintegrate under the shear mechanism. Therefore, mist is observed around prototype jets, in contrast to model jets. However, this effect takes place mainly beyond the herein applied integration limit of $h_{90}$ for air and trajectory considerations, so that it is a priori irrelevant.

Figure 2 compares jets with similar hydraulic features generated at the Kárahnjúkar dam chute end (including baffles instead of deflectors), but of different scales (Pfister et al. 2009). Figure 2(a) shows the model jet for $\lambda=45$, and Fig. 2(b) the prototype jet, with the jet visible in Fig. 2(a), whereas a dense mist covers the jet hiding the flow structure in Fig. 2(b). Note that these photos aim to illustrate scale effects related to the secondary
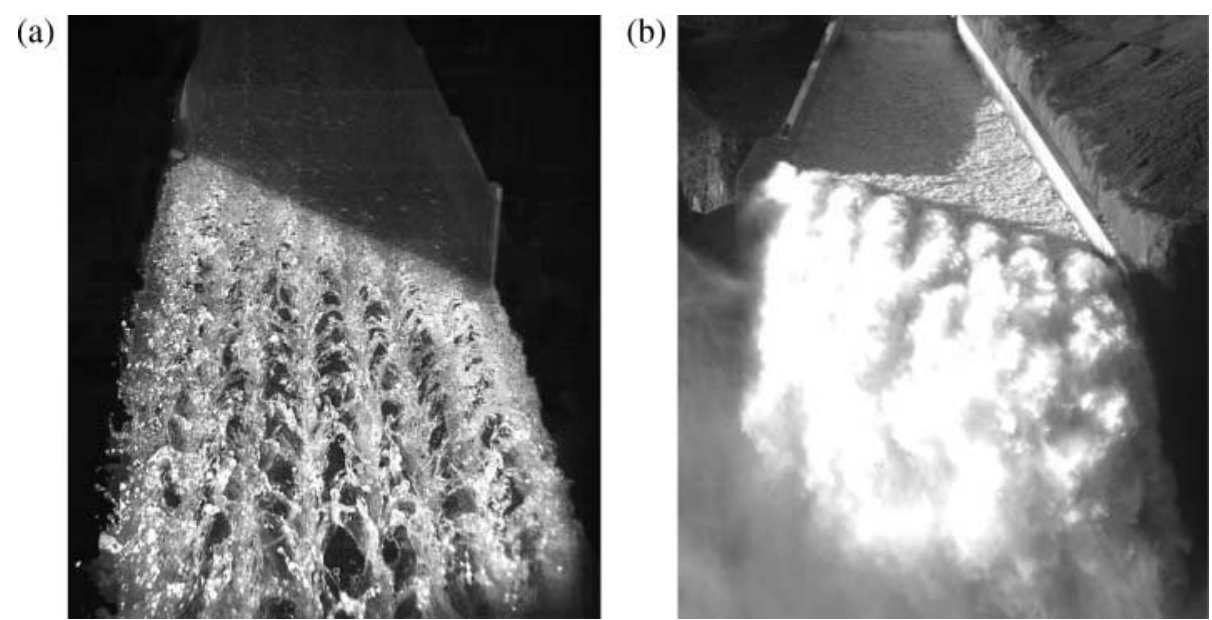

Figure 2 Jets of Kárahnjúkar dam spillway (Iceland) for otherwise identical conditions, (a) model with $\lambda=45$, (b) prototype (courtesy: Landsvirkjun) 

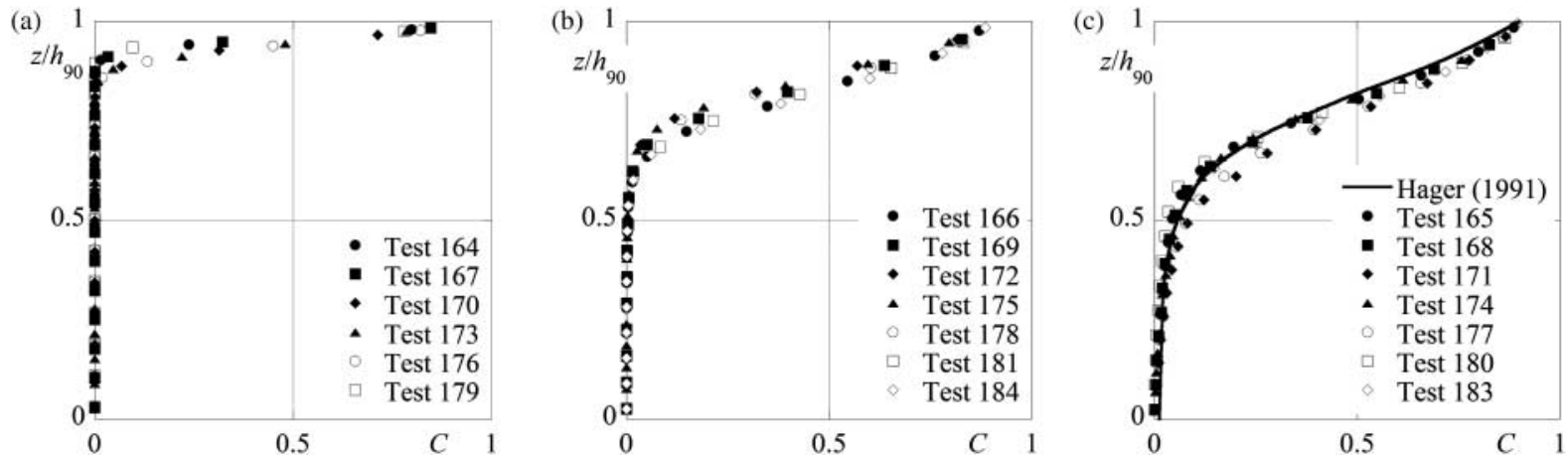

Figure 3 Approach flow air concentration profiles $C\left(z / h_{90}\right)$ for $C_{a o}=$ (a) $0.04-0.06$, (b) $0.13-0.17$, (c) $0.21-0.25$

jet disintegration, but not particularly the deflector-generated jet features.

\section{Approach flow conditions}

Straub and Anderson (1960) define the average cross-sectional air concentration $C_{a}$ as the integrated local air concentration distribution $C(z)$ over the flow section divided by the flow depth. For chute flow, the boundaries are represented by the chute bottom at $z=0$ and the flow surface at $h_{90}$ so that

$$
C_{a}=\frac{1}{h_{90}} \int_{0}^{h_{90}} C(z) \mathrm{d} z
$$

For a fully-developed air concentration profile in uniform chute air-water mixture flow $C_{a u}=0.75(\sin \phi)^{0.75}$ (Hager 1991), equivalent to $C_{a u}=0.23$ for the present set-up. Equation (3) has to be adapted to jets, so that the relevant flow thickness involves the lower (subscript $L$ ) $z_{L}$ and the upper (subscript $U$ ) $z_{U}$ jet trajectories (Fig. 1), both defined at $C=0.90$. Then, $z_{U}-z_{L}$ replaces $h_{90}$ and the integration limits are between $z_{L}$ and $z_{U}$.

The model air concentration profile $C(z)$ immediately upstream of the deflector has to be in agreement with characteristic two-phase flow profiles. As a reference, the data of Straub and Anderson (1960) analysed by Hager (1991) were used, providing a general relation for the uniform flow. All herein measured approach flow air concentration profiles are shown in Fig. 3 as $C\left(z / h_{90}\right)$. For the non-aerated approach flow with $C_{a o} \approx$ $0.04-0.06$, the profiles indicate a small air concentration near the flow surface, whereas black-water was measured below (Fig. 3a). For medium values from $C_{a o} \approx 0.13-0.17$, the air concentration near the flow surface increases (Fig. 3b). The profiles for the tests with $C_{a o} \approx 0.21-0.25$ are shown in Fig. 3(c) and compared with the uniform flow profile, resulting in excellent agreement $\left(R^{2}=0.99\right)$. It may, therefore, be concluded that the present approach flow concentration profiles are not affected by the jet-box, but are similar to those of Straub and Anderson (1960).

\section{Air concentration distributions}

\subsection{General}

The effect of pre-aerated approach flow on a specific model jet is shown in Fig. 4. The three model photos visualize jets of similar hydraulic conditions, except for pre-aeration. The deflector is located at left with its lip partially visible. The flow depth on the deflector lip of Fig. 4(a) is roughly $h_{90}=0.07 \mathrm{~m}$ and may serve as reference length. As is visible, mainly the jet surface is affected as pre-aeration increases. Along the entire jet, the turbulent flow surface becomes more pronounced and thicker as pre-aeration increases. Further, the black-water core within the jet starting at its take-off (on the left) is distinctively shorter for pre-aerated than for black-water approach flows.

Normalizing the $z$ coordinate as

$$
Z=\frac{z-z_{L}}{z_{U}-z_{L}}
$$

at each section $x$ (Fig. 1) results in cross-sectional air concentration profiles between the upper $Z=1$ and the lower $Z=0$ jet surfaces. Figure 5 shows typical profiles with and without pre-aeration, under otherwise similar conditions. The jet with non-aerated approach flow (Fig. 5a) has a black-water core with minimum cross-sectional air concentration of $C_{m}<0.01$ up to $x / h_{o} \cong 11$, whereas this length is only $x / h_{o} \cong 3.8$ for the preaerated jet (Fig. 5b). Downstream of the black-water core, the minima $C_{m}$ are located roughly at $Z_{m}=0.7 Z$ for the black-water approach flow, but only at around $Z_{m}=0.4 Z$ for pre-aeration. This again points at the dominant effect of pre-aeration on flow zones close to the upper jet surface (Fig. 4), whereas the lower jet zones are less affected. It is furthermore observed that the total air transport in terms of $C_{a}$ (Eq. 3) is larger for pre-aerated than for black-water approach flows.

Figure 6 shows the effect of pre-aeration $C_{a o}$ on the value $C_{a}(x=0)$ at jet take-off, both normalized with $C_{a u}$. All values of $C_{a}(x=0)$ are above those of $C_{a o}$ as indicated by the grey area, corresponding to an average air concentration at the jet take-off that is larger than in the approach flow, resulting from the additional surface roughness generated by a deflector (Ervine et al. 1995). It is further observed that as $C_{a o}$ increases, also $C_{a}(x=0)$ becomes larger. Yet there is a limit for $C_{a}(x=0)$ at $C_{a u}$, i.e. only few points are located above $C_{a}(x=0) / C_{a u}=1$. For a high degree of pre-aeration, e.g. $C_{a o} / C_{a u}=1$, the deflector effect on air entrainment is close to zero, whereas it reaches almost $0.7 C_{a u}$ for $C_{a o} / C_{a u}=0.2$. "Saturated" flows, as those with $C_{a o}=C_{a u}$, therefore hardly entrain additional air. 
(a)

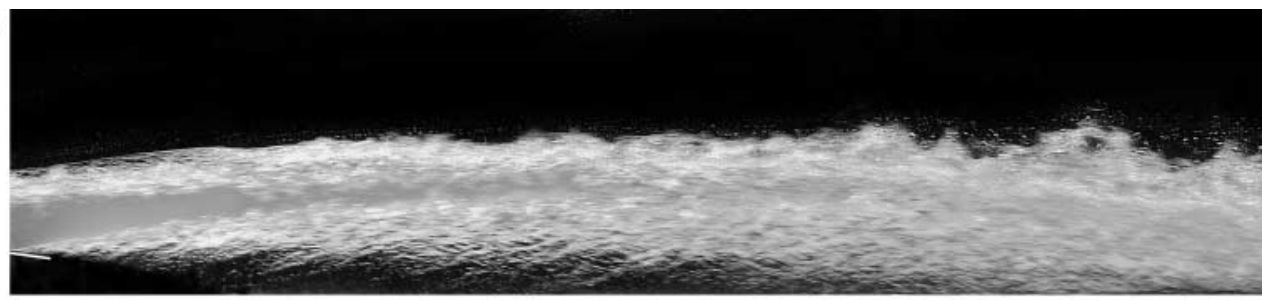

(b)

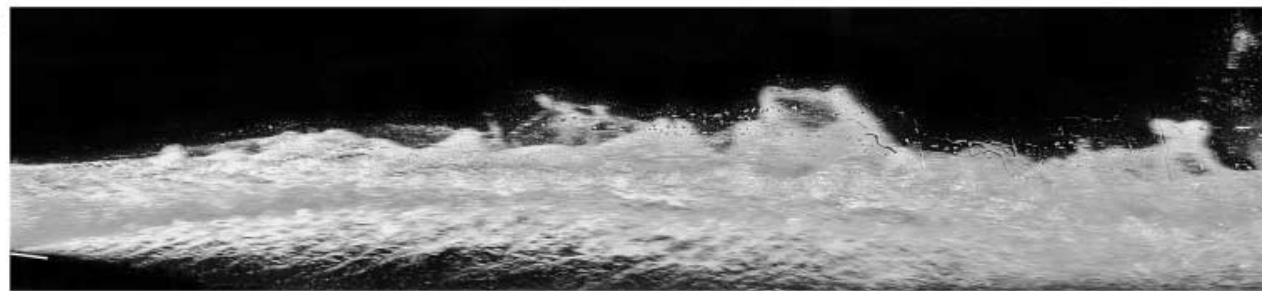

(c)

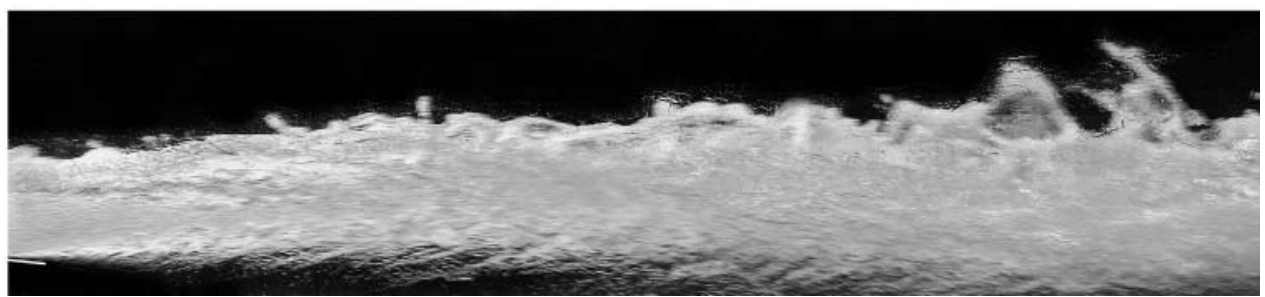

Figure 4 Model jets for $\mathrm{F}_{o}=9, h_{o}=0.065 \mathrm{~m}, \alpha=5.7^{\circ}, t=0.027 \mathrm{~m}$, and $C_{a o}=$ (a) 0.06 , (b) 0.15 , (c) 0.24 (Series S5, shutter speed 1/250 s)
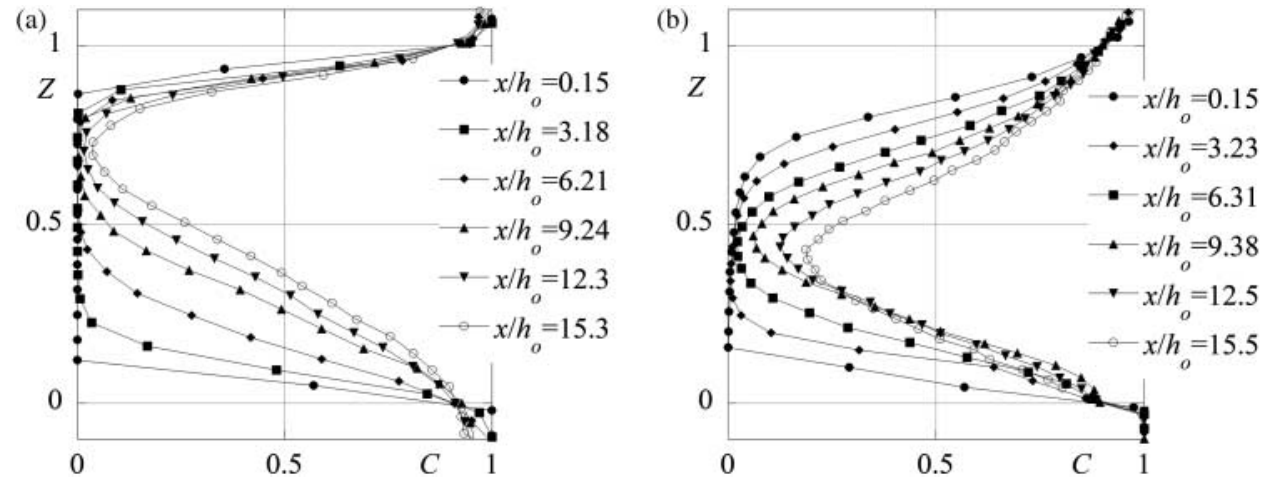

Figure 5 Air concentration profiles $C(Z)$ of tests (a) 176 with $C_{a o}=0.06$, (b) 177 with $C_{a o}=0.24$, for otherwise identical conditions

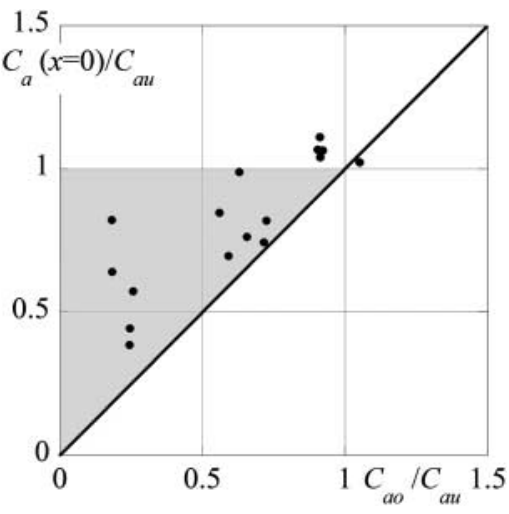

Figure $6 \quad C_{a}(x=0)$ compared with pre-aerated value $C_{a o}$, both normalized with $C_{a u}$

\subsection{Black water core length}

The black-water core length $L$ describes the distance between jet take-off at $x=0$ and the cross-section where $C_{m}=0.01$ within a jet profile (Pfister and Hager 2009a). Accordingly, a blackwater core with $C_{m}<0.01$ results along $L$, while the residual jet consists of a mixture flow with $C_{m}>0.01$. As shown in Fig. 7(a), a small pre-aeration of up to $C_{a o} \cong 0.15$ hardly reduces $L / h_{o}$, as compared with the reference value $C_{a o} \cong 0$, whereas an intense pre-aeration in the range of $C_{a o}=C_{a u}=0.23$ drastically reduces $L / h_{o}$. The derivation of $L$ as a function of the relevant parameters is given in the basic study. Here, the effect of $C_{a o}$ is considered, resulting in the additional term $-6 C_{a o}^{3}$ to the original equation. Accordingly, $L$ reduces with increasing $C_{a o}$, yet with a small effect for small $C_{a o}$, but for instance with $-7 h_{o}$ for $C_{a o}=0.25$ resulting in

$$
\begin{gathered}
\frac{L}{h_{o}}=74\left[\mathrm{~F}_{o}^{-1}(1+\tan \alpha)^{-0.5}(1+\sin \varphi)-6 C_{a o}^{3}\right] \\
\text { if } 4<L / h_{o}<20
\end{gathered}
$$

Equation (5) and the measured data compare well in Fig. 7(b), with the abscissa normalized as $\Phi_{L}=\left[\mathrm{F}_{o}^{-1}(1+\tan \alpha)^{-0.5}\right.$ 

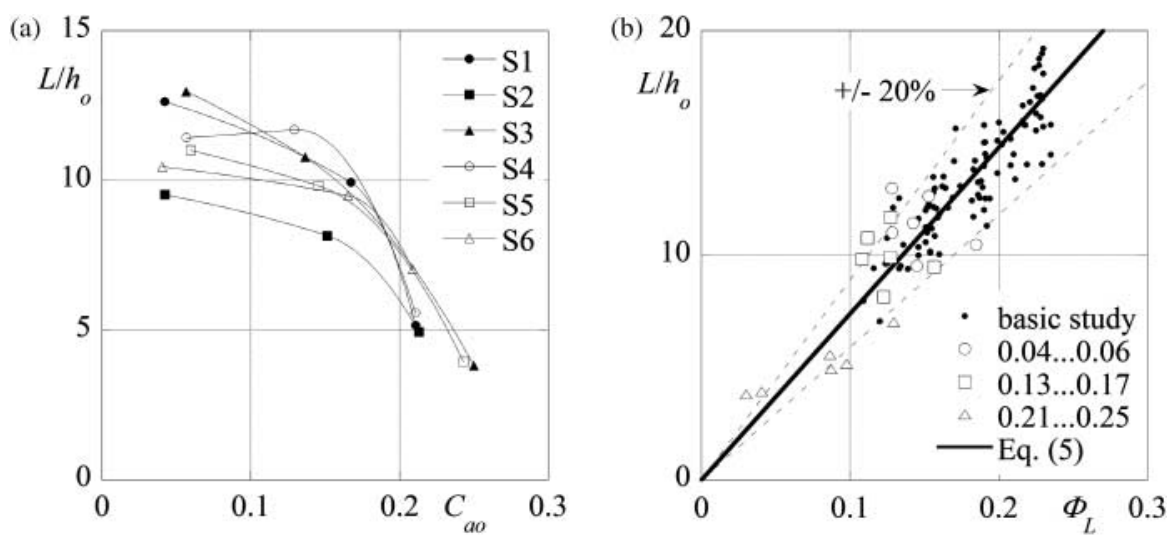

Figure 7 Relative black-water core length $L / h_{o}$ versus (a) $C_{a o}$ with test series numbers (Table 1), (b) $\Phi_{L}$ for various $C_{a o}$ ranges. Basic study refers to Pfister and Hager (2009a, 2009b)

$(1+\sin \varphi)]-6 C_{a o}^{3}$ from Eq. (5). The data of the basic study are also included. The coefficient of determination for all data is $R^{2}=0.82, R^{2}=0.79$ for only the basic study data, and $R^{2}=0.60$ for only the additional test data.

The jet air concentration development was found to depend on $L$ in the basic study, so that the streamwise coordinate $x$ was normalized as

$$
\chi=\frac{x}{L}
$$

Note that the present definition of $L$, using $C_{m}=0.01$ agrees with the basic study to allow for a data comparison, but is somehow arbitrary. On chutes with roughly $\varphi>15^{\circ}$, a uniform flow bottom air concentration exceeding 0.01 results, even increasing towards the flow surface. Then, the cross-sectional values of $C_{m}$ are above 0.01 , so that a different criterion has to be applied. As no such experiments including pre-aerating were conducted in the framework of the additional tests, the same criterion with respect to the non-aerated approach flow was selected.

\subsection{Minimum air concentration}

The vertical location of the minimum jet air concentration $C_{m}$ depends on the degree of approach flow pre-aeration. For the basic study and the additional tests with $C_{a o}<0.10$, all $C_{m}$ were located at $(0.6-0.8) Z$, as shown in Fig. 8(a) with $z_{m}\left(C_{m}\right)$ inserted in Eq. (4). For these jets, the aeration takes place mainly along the lower jet trajectory due to deflector-generated turbulence, whereas the upper jet surface remains comparatively smooth. For intermediate $C_{a o}$ values between 0.13 and 0.17 , the minima occur in the jet centre around $0.5 Z$, whereas for large $C_{a o}$ they were at roughly $(0.4-0.5) Z$. With increasing pre-aeration, the minimum air concentrations are consequently shifted towards the jet centre or even slightly below it, resulting from air transport close to the flow surface in the approach flow.

The minimum cross-sectional jet air concentration at $\chi=1$ is by definition $C_{m}=0.01$ and significantly increases further downstream. The test data were found to depend on both, $\chi$ and the degree of pre-aeration. If applying the equation
$C_{m}=0.1(\chi-1)^{1.5}+0.01$ from the basic study, the highly pre-aerated tests are over-predicted because $\chi$ is affected by preaeration (Eq. 5 inserted in Eq. 6). The term added in Eq. (5) partially corrects this over-estimation, so that only a slightly modified equation for $C_{m}$ as compared with the basic study was derived. The basic test data were also included in the data analysis, assuming that therein $C_{a o}=0.05$ equals to $C_{a o} / C_{a u}=0.2$. This applies for tests 164, 167, 170, 173, 176, and 179 without pre-aeration (Table 1). Then, the minimum cross-sectional air concentration $C_{m}$ is

$C_{m}=0.17(\chi-1)^{1.5}\left(1+\frac{C_{a o}}{C_{a u}}\right)^{-2.25}+0.01 \quad$ if $1 \leq \chi \leq 4$

The coefficient of determination for all data is $R^{2}=0.95, R^{2}=$ 0.96 for the basic study data, and $R^{2}=0.88$ for only the additional test data. The exponent relating to pre-aeration is negative, so that $C_{m}$ decreases with increasing $C_{a o}$. Figure $8(\mathrm{~b})$ compares the data of the basic and the present study with Eq. (7). The data for pre-aerated flow essentially collapse with the other values. The abscissa of Fig. 8(b) was normalized from Eq. (7) as $\Phi_{C m}=(\chi-1)\left(1+C_{a o} / C_{a u}\right)^{-1.5}$.

\subsection{Average air concentration}

The relevant parameter describing the jet features besides $C_{m}$ is the streamwise development of the average air concentration $C_{a}$. The data trend indicates that the identical equation as proposed in the basic study may be applied, taking into account the effect of pre-aeration via Eqs. (5) and (6). The present data and those of the basic study follow

$$
C_{a}=\tanh \left(0.4 \chi^{0.6}\right) \quad \text { if } 0.2 \leq \chi \leq 4
$$

The coefficient of determination for all data is $R^{2}=0.92, R^{2}=$ 0.93 for the basic study data, and $R^{2}=0.85$ for only the additional test data excluding values with $\chi<0.2$. Figure 9 compares the test data with Eq. (8). For intense jet aeration $C_{a} \rightarrow 0.9$, a 

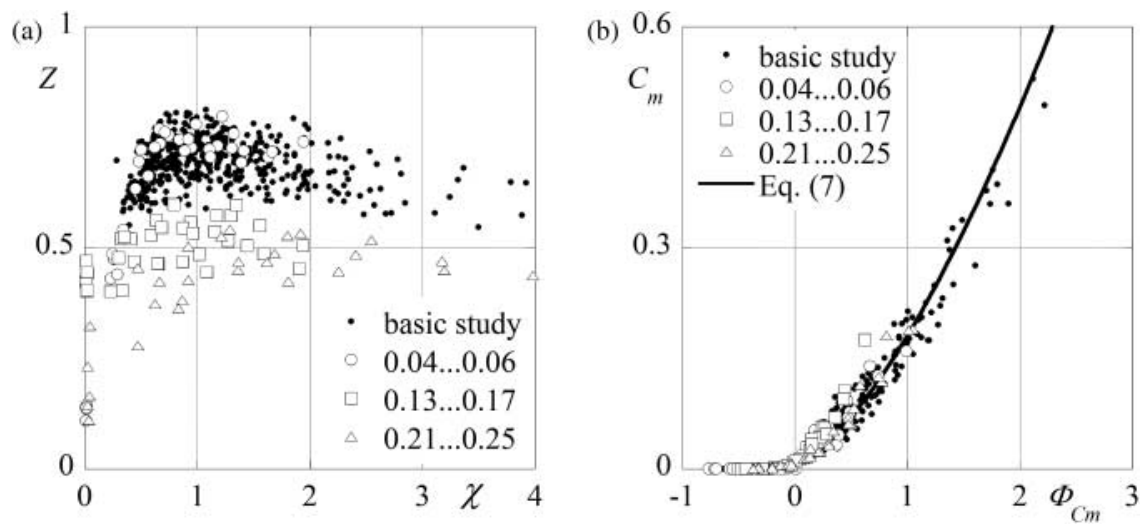

Figure 8 Location $C_{m}$ expressed with $Z(\chi)$ within jet, (b) $C_{m}\left(\Phi_{C m}\right)$ for various ranges of $C_{a o}$ according to legend. Basic study refers to Pfister and Hager (2009a, 2009b)

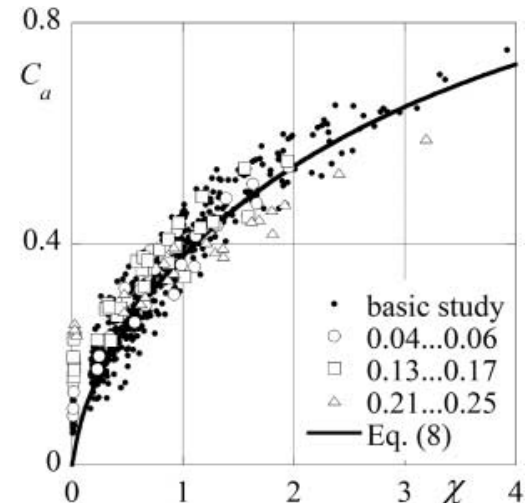

Figure 9 Test data and Eq. (8) for $C_{a}(\chi)$. Basic study refers to Pfister and Hager (2009a, 2009b)

development length of $\chi \rightarrow 9$ is necessary, which is beyond the application limit of Eq. (8), however.

In Fig. 9, some measured $C_{a}$ values at $\chi \approx 0$ are above those predicted by Eq. (8), including pre-aeration and the additional deflector-generated air entrainment, as explained in the context of Fig. 6. Points for large $C_{a o}$ are above the slightly- or not preaerated tests at $\chi \approx 0$. The effect on the further development of $C_{a}[\chi]$ is, however, independent of the initial discrepancies, and thus correctly included in Eq. (8), as also shown in Fig. 9.

\section{Trajectories}

\subsection{General}

The trajectory parabola as the basis of jet trajectory computation describes the curve of a mass point of constant density under the effect of gravity, depending on the take-off conditions and neglecting jet disintegration as well as the aerodynamic interaction. The computed trajectory thus represents a simplified approach, while effective trajectories observed on prototypes may differ from this model. The reason for this difference is based on uncertainties concerning $V_{o}, h_{o}$, the jet take-off angle differing from $\alpha$, jet disintegration and aerodynamic interactions.

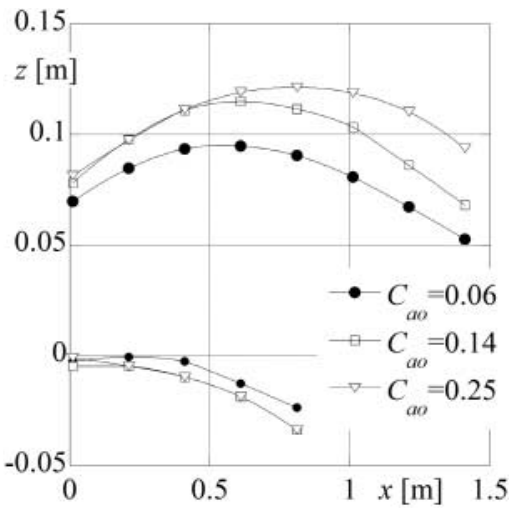

Figure 10 Non-normalized jet trajectories $z(x)$ of test series S3 (Table 1) indicating the effect of pre-aeration $C_{a o}$

The jet density reduces with flow distance, whereas the interaction with the surrounding air increases, both affecting the jet trajectory. Fully-aerated prototype jets therefore have shorter throw distances than theoretically derived. Following Kawakami (1973), who compared prototype data with the theoretical parabola, this effect is noticeable if $V_{o}>13 \mathrm{~m} / \mathrm{s}$. The $K$-factor in the equation of the Bureau of Reclamation (1987) also accounts for these effects. Pre-aerated approach flow adds to these phenomena (Schmocker et al. 2008).

The herein investigated jets were relatively short and only six series were collected, so that preliminary results are derived. Typical model jet trajectories are shown in Fig. 10 for test series S3 with non-normalized axes. As for all tests, pre-aeration clearly lifts the upper trajectory and marginally drops the lower trajectory, thereby spreading the jet in the vertical direction, as is necessary to increase $C_{a}[\chi]$. Furthermore, the take-off elevation of the upper trajectory at $x=0 \mathrm{~m}$ is different for the various preaeration ratios, as the trajectories represent the boundaries at $h_{90}$ with $C=0.90$ and not the black-water flow depth $h_{o}$.

From Fig. 4(c), the flow surface is strongly aerated for preaerated approach flow, so that its rough surface is subjected to major aerodynamic interaction. These zones contribute to mist production, but hardly include a relevant mass transport (Fig. 5b). Although the upper trajectories of pre-aerated approach flow jets 

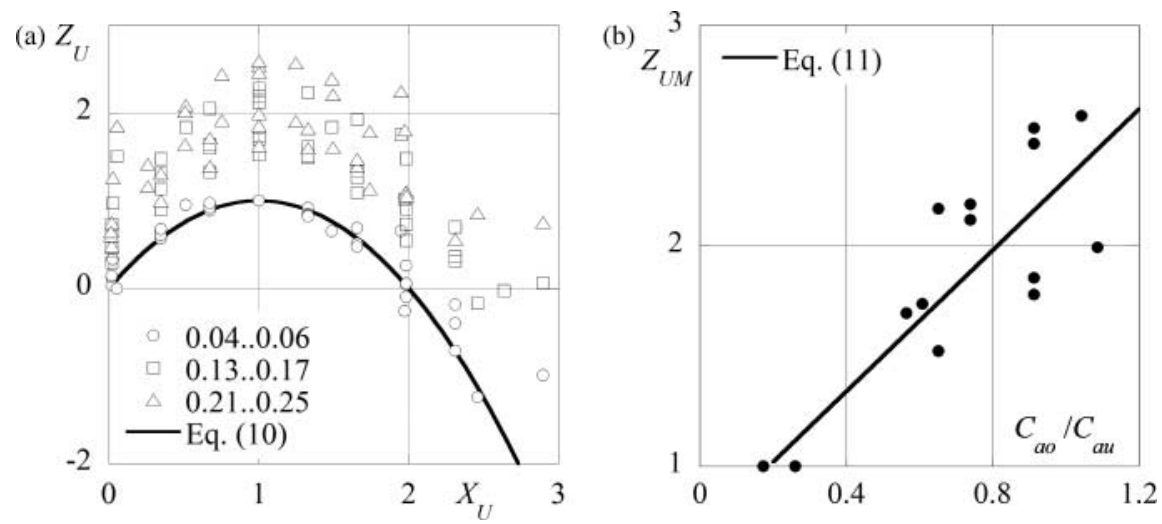

Figure 11 (a) Upper jet trajectories $Z_{U}\left(X_{U}\right)$ for ranges of $C_{a o}$ normalized with non-aerated approach flow, (b) $Z_{U M}$ versus pre-aeration $C_{a o} / C_{a u}$ compared with non-aerated approach flow

are above those of the non-aerated approach flow jets near takeoff, this part will break-up earlier and will not increase the total jet length.

For all tests, the lower jet trajectory is marginally lowered under pre-aerated approach flow. As the air concentrations are comparably smaller in the lower jet portion for pre-aerated approach flow (Fig. 5), slightly more mass is transported there. Therefore, for the effective jet length, the slightly reduced lower trajectories seem to be relevant.

\subsection{Upper jet trajectories}

As in the basic study, the upper jet trajectory is defined as

$$
Z_{U}=\frac{z_{U}-h_{o}}{z_{U M}-h_{o}}
$$

with $z_{U M}$ as maximum elevation of the upper trajectory, so that the take-off location at $x=0$ is close to the flow surface $Z_{U} \approx 0$. The maximum jet elevation is thus located at $Z_{U}=1$. Trajectory normalization as shown in Fig. 11(a) for non-aerated approach flow resulted in the basic study in

$$
Z_{U}=2 X_{U}-X_{U}^{2}
$$

As for the longitudinal coordinate $x$, the normalization again refers to the location of the maximum vertical jet elevation $Z_{U M}\left(X_{U M}\right)$. Using the maxima of the non-aerated approach flow as basis for trajectory normalization of the pre-aerated approach flow allows for detecting the effect of pre-aeration (Fig. 11a). Note that the jet trajectories of pre-aerated flows are all located above those of the basic tests, with a factor between 1.5 and 2.5. To derive a relation between these factors and the effect of the individual degree of pre-aeration, Fig. 11(b) gives the maximum values of the trajectories $Z_{U M}$ versus pre-aeration, with a base value of $Z_{U M}=1$ for the non-aerated approach flow. A linear trend line indicates that $\left(R^{2}=0.80\right)$

$$
Z_{U M}=1.6\left(\frac{C_{a o}}{C_{a u}}\right)+0.7
$$

Equation (11) is valid under the limitations of this study. An increased trajectory maximum is similar to a longer jet, if the parabolic jet geometry applies. In parallel, the present research indicates that pre-aerated jets have a rougher surface, which is more prone to secondary jet disintegration. Considering prototype experience (e.g. Kawakami 1973), the upper jet trajectory appears to hardly contribute to the total jet length. If the jet is sufficiently long and issued with a large velocity, so that primary jet disintegration is fully established and the secondary becomes dominant, then a "rupture" of the upper jet trajectory occurs (Fig. 12). Furthermore, the aerodynamic interaction decelerates the roughness elements at the jet surface and separated water lumps, so that their effective throw length is reduced. However, the basic model study involves values of only $V_{o} \leq 7.5 \mathrm{~m} / \mathrm{s}$ and short jets of up to $2.4 \mathrm{~m}$ length, so that neither "rupture" of the upper trajectory nor deceleration were observed. The values of the upper streamwise maximum $x_{U M}$ seem to be constant or increase slightly under pre-aeration. However, given the limited data set, no definite conclusion is available.

\subsection{Lower jet trajectories}

The lower jet trajectory is similarly defined as the upper, but with a reference height at the deflector lip, so that

$$
Z_{L}=\frac{z_{L}}{z_{L M}}
$$

with $z_{L M}$ as maximum elevation of the lower trajectory. Then, the take-off location at $x=0$ is at the deflector lip, i.e. $Z_{L} \approx 0$, and the maximum elevation $Z_{L M}\left(X_{L M}\right)$ is located at $Z_{L}=1$. If again normalizing the streamwise trajectory as the parabola

$$
Z_{L}=2 X_{L}-X_{L}^{2}
$$

using the maximum location as reference results in Fig. 13(a), with the non-aerated approach flow data taken as reference. The values for pre-aerated approach flow were added using the normalization of $X_{L}$ and $Z_{L}$ of the related non-aerated data. As the pre-aerated trajectories are shorter (Fig. 10), they are below those of non-aerated approach flows. 


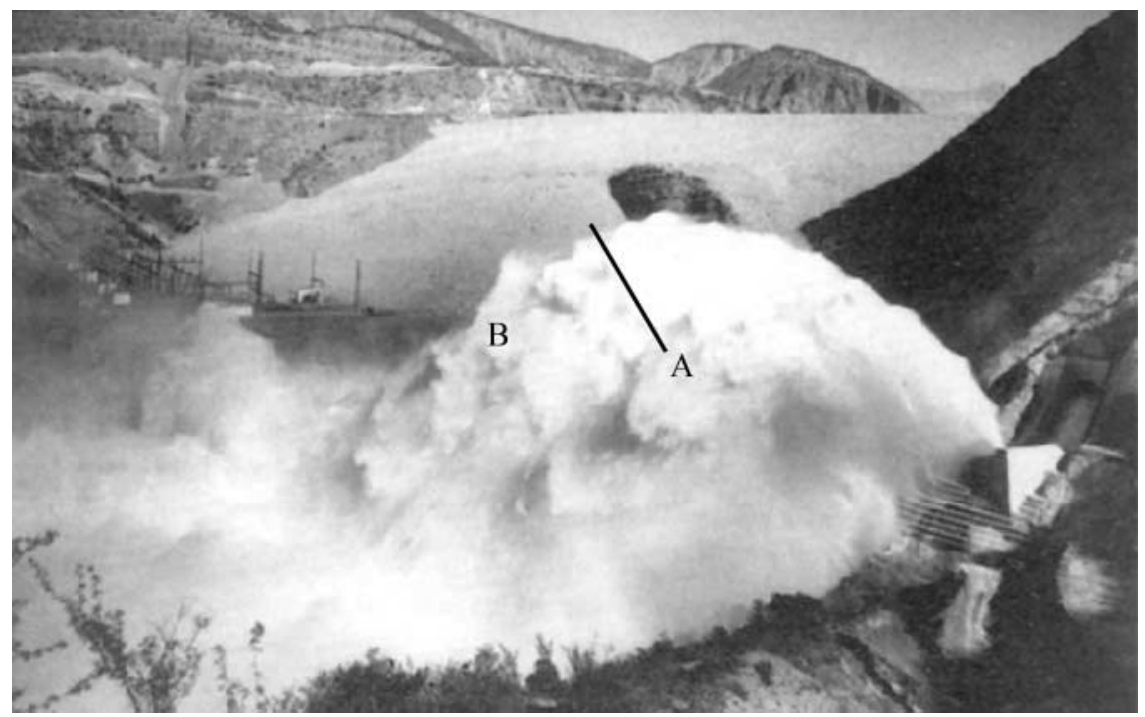

Figure 12 Prototype jet with "rupture" of upper jet trajectory at A and shortened trajectory along B (Vischer and Hager 1995, for a flip bucket-generated jet)
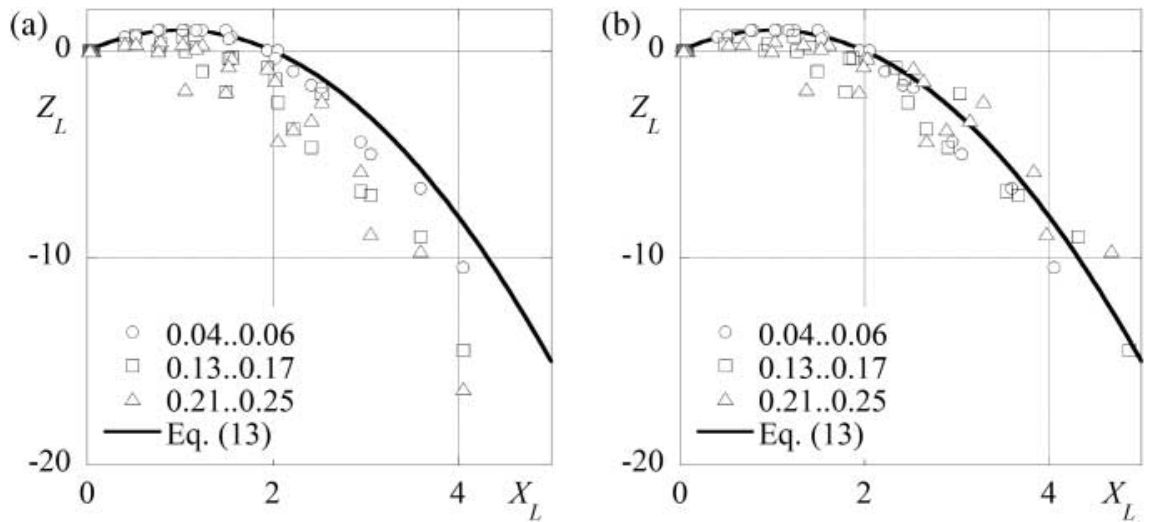

Figure 13 Lower jet trajectories $Z_{L}\left(X_{L}\right)$ for ranges of $C_{a o}$, (a) normalized with non-aerated approach flow, (b) $X_{L}$ coordinates multiplied with factor 1.2 for $C_{a o}=0.13$ to 0.17 , and 1.3 for $C_{a o}=0.21$ to 0.25

The interpretation of the modified jet length is challenging due to the few data, so that a pragmatic approach is proposed. Using the streamwise coordinate of the non-aerated approach flow as reference, the other values were multiplied with a factor so that they essentially collapse with Eq. (13). This factor is 1.2 for $C_{a o}=0.13$ to 0.17 and 1.3 for $C_{a o}=0.21$ to 0.25 as compared with the trajectory of non-aerated approach flows (Fig. 13b). Note however that the model indicates reduced lower jet trajectories of the order of $80 \%$ of the non-aerated throw length as reference for considerably pre-aerated approach flow. This effect appears to be stronger for long prototype jets (Kawakami 1973). Furthermore, Fig. 13 indicates that the maximum jet elevations are underestimated if the approach flow is pre-aerated. Nonetheless, no trend as in Eq. (8) for the upper trajectory is derived.

\section{Conclusions}

The effect of pre-aerated approach flow on deflector-generated jets at the end of chutes was investigated in a physical model.
The results were compared with a former systematic study, but now only varying the approach flow depth, the deflector height, the approach flow Froude number between 6.2 and 9.3, and the deflector angle between $5.7^{\circ}$ and $11.3^{\circ}$. As a result, the effects of pre-aeration on these jets are:

- Photos indicate that the upper jet surface is rougher for preaerated than for non-aerated approach flow, but that the lower jet surface is hardly affected,

- Air concentration profiles within the jet are affected by preaeration. For non-aerated approach flow, mainly the lower jet portion is aerated, while the upper portion is more aerated for pre-aerated approach flow,

- Average air concentration at jet take-off is similar to or higher than the degree of pre-aeration. The relative local air entrainment potential at the deflector is higher for small pre-aeration rates,

- Black water core length reduces with pre-aeration, so that the cross-sectional minimum and average air concentrations increase. Equations are given to estimate these values, 
- Minimum air concentrations within a profile are located in the upper jet half for non-aerated approach flow, but at the centre or slightly below it for pre-aerated flow,

- Upper jet trajectories of pre-aerated approach flow are above those of the non-aerated approach flow. With the normalization selected, they vertically exceed the base jet resulting from non-aerated approach flow by a factor of $1.5-2.5$,

- Streamwise lengths of lower jet trajectories are slightly reduced (to some 80\%) for pre-aerated as compared with non-aerated approach flows,

- Observations of the disintegration mechanisms and of prototype jets indicate that the lower jet trajectory is relevant to the total jet throw lengths, if long and fast jets are considered, and

- Scale effects related to model jets are discussed.

\section{Acknowledgements}

The authors thank Ms Jill Lucas, VAW, ETH Zurich, for having conducted the model tests.

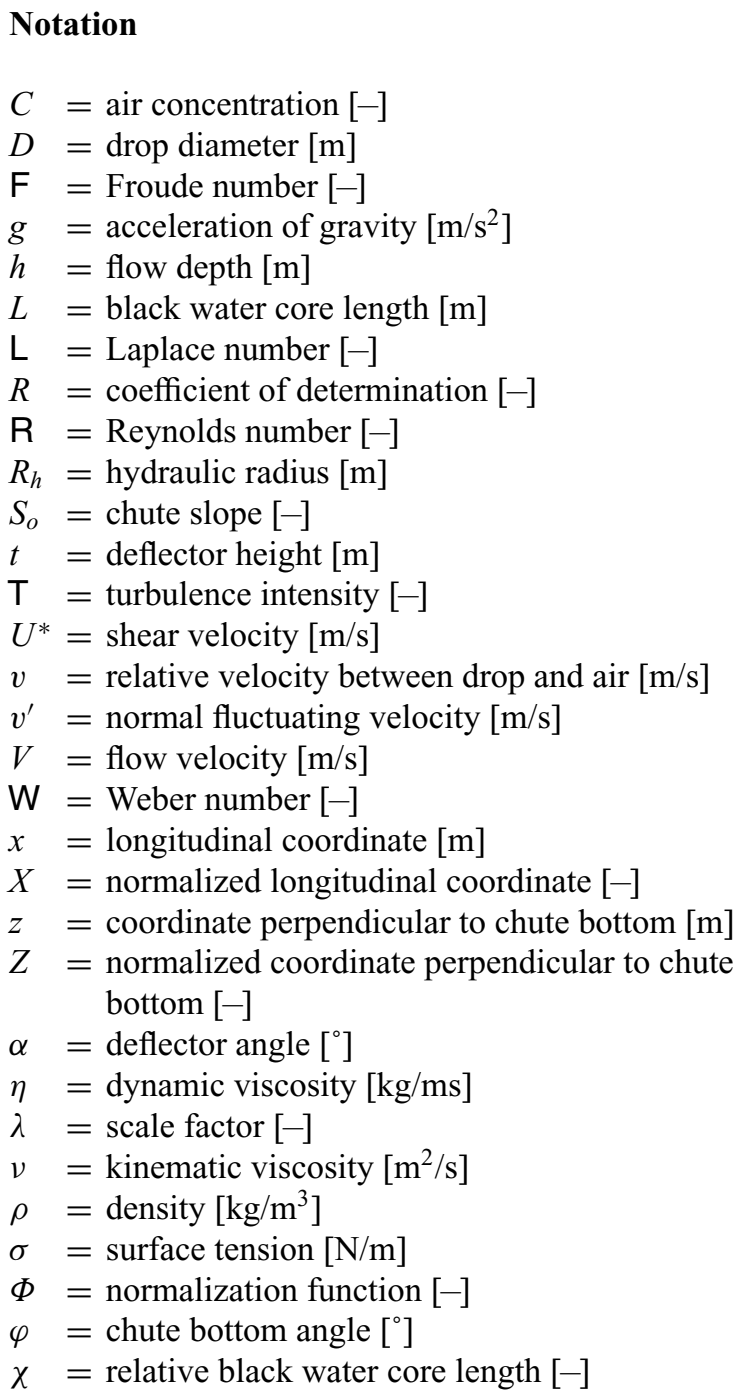

Subscripts

$a=$ average

$A=$ air

$D=$ drop

$L=$ lower

$m=$ minimum

$M=$ maximum

$o=$ approach flow

$u=$ uniform flow

$U=$ upper

$90=$ mixture air-water flow

\section{References}

Baumgarten, C. (2003). Modellierung des Kavitationseinflusses auf den primären Strahlzerfall bei der HochdruckDieseleinspritzung (Modeling of cavitation effect on the primary jet disintegration at high-pressure diesel injection). Fortschritt-Bericht 12(543), VDI Verlag GmbH, Düsseldorf [in German].

Bollaert, E.F.R., Schleiss, A.J. (2003a). Scour of rock due to the impact of plunging high velocity jets 1: A state-of-the-art review. J. Hydraulic Res. 41(5), 451-464.

Bollaert, E.F.R., Schleiss, A.J. (2003b). Scour of rock due to the impact of plunging high velocity jets 2: Experimental results of dynamic pressures at pool bottoms and in one- and twodimensional closed end rock joints. J. Hydraulic Res. 41(5), 465-480.

Bureau of Reclamation (1987). Design of small dams, $3^{\text {rd }} \mathrm{ed}$. US Department of the Interior, United States Government Printing Office, Denver, 365-387.

Ervine, D.A., Falvey, H.T. (1987). Behavior of turbulent water jets in the atmosphere and in plunge pools. Proc. Inst. Civil Engrs. 83(2), 295-314.

Ervine, D.A., Falvey, H.T., Kahn, A.R. (1995). Turbulent flow structure and air up-take at aerators. J. Hydropower and Dams 2(4), 89-96.

Falvey, H.T., Ervine, D.A. (1988). Aeration in jets and high velocity flows. Model-Prototype Correlation of Hydraulic Structures, 25-55, P.H. Burgi, ed. ASCE, New York.

Hager, W.H. (1991). Uniform aerated chute flow. J. Hydraulic Eng. 117(4), 528-533.

Heller, V., Hager, W.H., Minor, H.-E. (2005). Ski jump hydraulics. J. Hydraulic Eng. 131(5), 347-355.

Hwang, S.S., Liu, Z., Reitz, R.D. (1996). Breakup mechanism and drag coefficients of high-speed vaporizing liquid drops. Atomization and Sprays 6(3), 353-376.

Juon, R., Hager, W.H. (2000). Flip bucket without and with deflectors. J. Hydraulic Eng. 126(11), 837-845.

Kawakami, K. (1973). A study on the computation of horizontal distance of jet issued from ski-jump spillway. Proc. JSCE 219, 37-44 (in Japanese) [Trans. JSCE 5, 96-97, abridged translation into English]. 
Khatsuria, R.M. (2005). Hydraulics of spillways and energy dissipators. Dekker, New York.

Krzeczkowski, S.A. (1980). Measurement of liquid droplet disintegration mechanisms. Intl. J. Multiphase Flow 6(3), 227-239.

Nezu, I., Nakagawa, H. (1993). Turbulence in open-channelflow. Balkema, Rotterdam.

Novak, P., Moffat, A.I.B., Nalluri, C., Narayanan, R. (2007). Hydraulic structures, $4^{\text {th }}$ ed. Taylor \& Francis, London.

Ohnesorge, W. (1936). Die Bildung von Tropfen an Düsen und die Auflösung flüssiger Strahlen (The generation of drops at nozzles and the disintegration of liquid jets). Zeitschrift für Angewandte Mathematik und Mechanik 16(5), 355-358 [in German].

Orlov, V. (1974). Die Bestimmung des Strahlsteigwinkels beim Abfluss über einen Sprungschanzenüberfall (Determination of the jet rise angle at flow over a ski jump). WasserwirtschaftWassertechnik 24(6), 320-321 [in German].

Pagliara, S., Hager, W.H., Minor, H.-E. (2006). Hydraulics of plane plunge pool scour. J. Hydraulic Eng. 132(5), $450-461$.

Pfister, M., Hager, W.H. (2009a). Deflector-generated jets. J. Hydraulic Res. 47(4), 466-475.

Pfister, M., Hager, W.H. (2009b). Air concentration characteristics of drop- and deflector-generated jets. $33^{\text {rd }}$ IAHR World Congress Vancouver (10230), 4909-4916.

Pfister, M., Berchtold, T., Lais, A. (2009). Kárahnjúkar dam spillway: Optimization by hydraulic model tests. Advances in Water Resources and Hydraulic Engineering, C.K. Zhang and H.W. Tang, eds. Tsinghua University Press, Beijing, 6, 2106-2111.

Pfister, M., Hager, W.H. (2010). Chute aerators. I: Air transport characteristics. J. Hydraulic Eng. 136(5), 352-359.
Pfister, M., Lucas, J., Hager, W.H. (2011). Effect of pre-aerated approach flow on the aeration of deflector-generated jets. $34^{\text {th }}$ IAHR World Congress Brisbane, 2554-2561.

Pfister, M. (2012). Jet impact angle on chute downstream of aerator. $4^{\text {th }} I A H R$ Symp. Hydraulic Structures, Porto, CD, 7, 1-8.

Pfister, M., Chanson H. (2012). Discussion of Scale effects in physical hydraulic engineering models. J. Hydraulic Res. [in press].

Rajaratnam, N. (1976). Turbulent jets. Elsevier, New York.

Schley, C.A. (1994). Grobstruktur-Simulation turbulenter Strömungsphänomene im Hinblick auf destabilisierende Prozesse beim Strahlzerfall in Hochdruck-Raketentriebwerken (Rawstructural simulation of turbulent flow phenomena relative to the destabilizing processes at jet disintegration in highpressure reactors). Forschungsbericht 94-28, Institut für chemische Antriebe und Verfahrenstechnik, Lampoldshausen [in German].

Schmocker, L., Pfister, M., Hager, W.H., Minor, H.-E. (2008). Aeration characteristics of ski jump jets. J. Hydraulic Eng. 134(1), 90-97.

Steiner, R., Heller, V., Hager, W.H., Minor, H.-E. (2008). Deflector ski jump hydraulics. J. Hydraulic Eng. 134(5), $562-571$.

Straub, L.G., Anderson, A.G. (1960). Experiments on selfaerated flow in open channels. Trans. ASCE 125, 456- 486.

Toombes, L., Chanson, H. (2007). Free-surface aeration and momentum exchange at bottom outlet. J. Hydraulic Res. 45(1), 100-110.

Vischer, D.L., Hager, W.H. (1995). Energy dissipators. Balkema, Rotterdam.

Volkart, P. (1980). The mechanism of air bubble entrainment in self-aerated flow. Intl. J. Multiphase Flow 6(5), 411-423. 